\title{
CARLOS COSSIO A TREINTA AÑOS DE SU MUERTE.
}

\author{
Celina A. Lértora Mendoza \\ Universidad Nacional del Sur, Argentina \\ fundaciónfepai@yahoo.com.ar
}

\section{RESUMEN}

El Artículo trata sobre el pensamiento de Carlos Cossio, quien fuera profesor de Filosofía del Derecho en la Universidad de la Plata y en Buenos Aires, desde 1946 a 1975, cuya contribución a las demás disciplina filosóficas fue valiosa: fue fundador y presidente del Instituto Argentino de Filosofía Jurídica y Social. Fue el primero en incorporar a las cátedras de Filosofía del Derecho los estudios de Hans Kelsen, Oliver W. Holmes y Karl Marx. Su investigación iusfilosófica se inspira en Kant, Husserl y Heidegger. Carlos Cossio presenta las relaciones de justicia de una manera menos estática e impersonal. Sostiene que cualquier actividad humana tiene que ser entendida, en función de su situación, porque la vida humana es vivida siempre en situaciones (el "estar-siendo-en el-mundo" heideggeriano) La dependencia en que se encuentra cada acto humano, en tanto conducta, es una relación de estructura vital, es decir, una estructura en la cual aparecen cambios a la par que cualitativos.

\section{PALABRAS CLAVES}

Carlos Cossio, Filosofía, derecho.

\section{ABSTRAC}

The article deals with the thinking of Carlos Cossio, who was professor of Philosophy of Law at the University of La Plata and Buenos Aires, from 1946 to 1975, whose contribution to the other philosophical disciplines was valuable: he was founder and president of the Argentine Institute of Legal and Social Philosophy. He was the first to incorporate the studies of Hans Kelsen, Oliver W. Holmes and Karl Marx into the chairs of Philosophy of Law. His iusophosophical investigation is inspired by Kant, Husserl and Heidegger. Carlos Cossio presents the relations of justice in a less static and impersonal way. He argues that any human activity has to be understood, according to his situation, because human life is always lived in situations (Heidegger's "being-in-the-world"). The dependency in which each human 
act is found, in so much behavior, it is a relation of vital structure, that is to say, a structure in which changes appear at the same time that qualitative.

\section{KEYWORDS}

Carlos Cossio, Philosophy, law.

\section{DATOS BIOGRÁFICOS Y REPERCUSIÓN}

Carlos Cossio nació en San Miguel de Tucumán el 3 de febrero de 1903. Estudió abogacía y desde muy joven se dedicó a la vida académica. Se especializó en filosofía del derecho, y desde esta inquietud exploró los temas centrales de la filosofía, siendo un buen conocedor del pensamiento filosófico alemán contemporáneo. Fue profesor de Filosofía del Derecho en la Universidad de la Plata (1934-1946) y en la de Buenos Aires (1946-1956 y 1973-1975).

Fue fundador y presidente del Instituto Argentino de Filosofía Jurídica y Social. Falleció en Buenos Aires, el 24 de agosto de 1987, a causa de un accidente doméstico.

Cossio es posiblemente el iusfilósofo argentino de más amplia y reconocida trayectoria. Fue el primero en incorporar a las cátedras de Filosofía del Derecho el estudio de Hans Kelsen, Oliver W. Holmes y Karl Marx. Personalmente, en su investigación iusfilosófica, parte de concepciones ontológicas y gnoseológicas inspiradas en Kant, Husserl y Heidegger, autores por los que pasa, según él, el nervio del pensamiento contemporáneo. Conoció las teorías de Max Scheler y Nicolai Hartmann, autores de mucho predicamento en Sudamérica, como él mismo lo reconoce, pero considera que la obra de ellos es inaceptable por el carácter hipotético de que adolece. Su caracterización del derecho (Cossio, L. 1964, p. 202) como vida humana plenaria considerada desde cierto ángulo, o como [...] conducta humana en su interferencia intersubjetiva ha sido adoptada por numerosos autores en Argentina y fuera de ella. Su pensamiento ha resultado interesante en los ámbitos de la filosofía del derecho porque presenta las relaciones de justicia en una forma menos estática e impersonal, basándose en una relación comunitaria, y en ese sentido se separa tanto del antiguo 
derecho natural como de los enfoques positivistas. Asimismo incorpora una teoría de los valores con una propuesta de su articulación (el llamado "plexo axiológico") que completa y mejora la propuesta de Scheler.

Su obra tuvo una amplia repercusión. En la Facultad de Derecho de la Universidad de Buenos Aires se formó un grupo de discípulos que desde los años 60 escribieron numerosos artículos y también tratados de filosofía del derecho y de introducción al derecho basándose en gran parte en sus ideas. Su polémica con Kelsen despertó también interés tanto en Argentina como en Brasil, en Estados Unidos y en otros países, y muchos juristas tomaron partido por uno u otro. El conjunto de personas y trabajos resultantes de defender las posiciones iusfilosóficas de Cossio es conocido con el nombre de "escuela argentina".

\section{REFLEXIÓN ANTROPOLÓGICA}

\section{a) La esencia o naturaleza humana}

Hay que señalar, en primer lugar, que la cuestión de la naturaleza humana no se plantea en un marco estrictamente antropológico, sino que debe rastrearse en la ontología (teoría de los objetos) que sirve de soporte a su concepción del derecho, fundado a su vez en una concepción de la acción humana que lleva implícita (aunque no tematizada en forma autónoma) una antropología filosófica.

Como presupuesto de esta elaboración acerca de la conducta humana jurídica, plantea una teoría de los objetos de índole fenomenológica, inspirada en Husserl (Cossio, L. 1967, p. 27). Clasifica los objetos en cuatro clases: ideales, naturales, culturales y metafísicos. Cada uno de ellos ostenta sendas características en función de tres coordenadas: la existencia, la experiencia y la valoración. Los objetos ideales (por ejemplo los entes matemáticos) son irreales (no tienen existencia propia), no están en la experiencia y son neutros al valor; los entes naturales (por ejemplo un árbol) son reales (tienen existencia propia), están en la experiencia y son neutros al valor); los objetos culturales (por ejemplo un cuadro) son reales, están en la experiencia y son valorables positiva o negativamente; los objetos metafísicos (por ejemplo Dios) son reales (o se piensan como tales), no están en la experiencia y son valorables positiva o negativamente. 
Avanzando en el análisis antropológico, divide los objetos culturales en mundanales y ecológicos. Son "objetos mundanales" o "vida humana objetivada" todas aquellas cosas en que intervino la actividad del hombre, y que constituyen su mundo. En cambio, para designar a la conducta, a la vida humana viviente, acuña la expresión "objetos egológicos" (de "ego": yo), indicando con esto que el substrato del sentido es la propia conducta del sujeto actuante (Cossio, L. 1963, p. 117 y 1845, p. 72 ss). La característica común de ambas clases de objetos es que su ser es un ser-unsentido. Todo producto cultural (producto de una actividad del hombre) es "vida humana objetivada".

Cualquier actividad humana tiene que ser entendida, a su vez, en función de su situación, porque la vida humana es vivida siempre en situaciones (Cossio, A. 1960, p. 921, ss) (el "estar-siendo-en-el-mundo" heideggeriano). La dependencia en que se encuentra cada acto humano, en tanto conducta, es una relación de estructura vital, es decir, una estructura en la cual aparecen cambios cuantitativos a la par que cualitativos.

\section{b) Posturas gnoseológicas}

Cossio aborda la cuestión gnoseológica en función de su interés propio, que es la ciencia del derecho, y más específicamente la relación gnoseológica entre conducta y norma.

También aquí fundamenta su teoría iusfilosófica en un planteo más general, de índole gnoseológica, vinculado a su clasificación ontológica de los objetos. Afirma que cada clase de objetos (con excepción de los metafísicos, de los cuales no tenemos conocimiento en sentido propio) es captada por un acto gnoseológico específico, que se corresponde con una estructura gnoseológica y un método. Esta pluralidad se justifica en estos términos: "si esta heterogeneidad de los objetos hace ver que no es posible ir a conocerlos con un método único, también hace ver al propio tiempo que debemos elucidar qué método utilizaremos para conocer estos objetos, porque es evidente que el conocimiento depende de una adecuación del método con el objeto. Si el método no es adecuado a la naturaleza del objeto, divagaríamos muchos pero no obtendríamos un conocimiento científico" (Cossio, L. 1967, p. 31).

Los objetos ideales son captados por intelección y derivación, su estructura gnoseológica es un todo simple y cerrado y el método adecuado es el racional-deductivo. Los objetos naturales son captados por la percepción 
y la explicación, su estructura gnoseológica es un todo compuesto y abierto y el método adecuado es el empírico inductivo. Los objetos culturales son captados por la vivencia y la comprensión, su estructura gnoseológica es un todo simple y abierto y el método correspondiente es el empíricodialéctico.

\section{c) Realización, posibilidades y límites el hombre ante la naturaleza, Dios y la religión, el Estado, la escuela, la sociedad civil, la familia, el género, las razas, las generaciones, la solidaridad, los derechos humanos, etc.}

Tal como ya se ha indicado, Cossio es un jurista y un iusfilósofo, y por tanto todas sus elaboraciones respecto a otros aspectos de la filosofía general se enuncian en función de su interés central. Su posición sobre la naturaleza y Dios puede rastrearse en su teoría de los objetos, a la que ya me he referido. La naturaleza es el conjunto de los seres que constituyen los objetos naturales, con los caracteres ya vistos. El acto cognitivo específico del hombre frente a la naturaleza constituirá, en su nivel superior, la ciencia empírica.

Dios es uno de los objetos metafísicos (cuarta categoría en su clasificación ontológica), es más, sería el "caso típico", pues Dios "que siempre es pensado como la realidad realísima, es decir, que tiene existencia; no está en la experiencia pues nadie lo puede ver, tocar u oír; y además está concebido siempre como la suma de los valores: la suma bondad, la suma belleza, la suma sabiduría" (Cossio, L. 1967, p. 31). Pero aclara a continuación que dentro de la filosofía existencial, a la que adhiere, sólo las categorías que corresponden al hombre como existenciarios, incluyendo los valores puros, son de verdad objetos metafísicos. De modo que su posición frente a Dios puede caracterizarse como agnosticismo; Dios es pensado con las notas indicadas, por la generalidad de los hombres, pero en tanto objeto metafísico no existe un acto gnoseológico propio que permita su captación, por lo cual resulta un incognoscible, y por ende no hay un método adecuado ni ciencia propiamente dicha acerca de Dios. Algunos párrafos incidentales, a propósito de la crítica egológica a la teoría iusnaturalista, pueden ilustrar mejor su concepto al respecto: Dios no es un objeto propiamente ontológico sino teológico (es decir, supone la fe de quien cree en su existencia) y por eso no puede fundar ontológicamente el derecho natural, como pretenden los escolásticos (Cossio, L. 1967, p. 257). 


\section{d) Significado de los valores en su pensamiento}

Cossio inscribe la teoría axiológica en el ámbito de la vida humana y de los objetos culturales que, como he visto, tienen el carácter esencial de ser valorables positiva o negativamente. Todo objeto es valorable en cuanto entra en la esfera de la vida humana y se transforma en objeto cultural:

"En realidad, esta referencia a valores es propia de la vida humana. Así, sin duda, nos puede resultar hermosa una puesta de sol; pero lo que es hermoso en esa circunstancia es el mundo de quien tiene sensibilidad para percibir el fenómeno de ese modo. No existe la noción de paisaje independientemente de la noción de espectador, que la integra; el paisaje es siempre el escenario de alguien que real o virtualmente lo contempla. Quiere decir, pues, que estos objetos naturales aparecen también como neutros al valor, en tanto son en sí meros objetos de las ciencias naturales" (Cossio, L. 1945, pp. 29-30).

Los juicios de valor, por otra parte, no son independientes del sujeto que los enuncia, no son neutrales, como son los juicios fundados en la intelección y la explicación. El sujeto que los enuncia está implicado en los juicios de valor, pero no como mero espectador, sino como quien toma una posición ${ }^{1}$.

Cossio ha formulado una teoría de los valores específica para el mundo jurídico, conocida como "plexo axiológico". Sin embargo, advierte que esta formulación regional de los valores requiere un marco más amplio y que los valores normativos deben basarse en valores pre-normativos. A la pregunta de cómo se fundan estos valores pre-normativos, Cossio sostiene que dichos valores no pueden ser ideas de ninguna especie (ni imaginarias humanas, ni platónicas), tampoco son ideas regulativas, puesto que admite los valores como existenciarios o sea, categorías ontológicas de futuridad, proyectivas del ser del hombre que programan. En la teoría egológica que él propone, los valores se resuelven, como existenciarios, en "valores proyectivos puros", los que "sólo son la mejor posibilidad infraestructural contenida en una situación" (Cossio, A. 1967, p. 250.

El siguiente párrafo ilustra su posición acerca de la naturaleza de los valores: “...la teoría egológica muestra que los valores positivos puros

1 Esta distinción entre actos de aprehensión y de toma de posición está inspirado en los análisis de Husserl y Scheler, como el mismo Cossio reconoce expresamente. 
resultan ser existenciarios de futuridad en el ser del hombre, categorías proyectivas propias de su temple emocional. Estas categorías -cuya objetividad ya hemos establecido- no tienen la objetividad que como categorías confieren, surgiendo, al modo kantiano, de una hipótesis trascendental. En el análisis egológico ellas emergen como una relación de ser cuando este ser se manifiesta; por eso ellas se radican en la situación en cuanto que ésta es un todo de posibilidades y en tanto que el sujeto toma de la situación su propio sentido al ponerse en situación mediante la posibilidad que eligiere. [...] Además, por tratarse de una relación de ser, los valores así entendidos pueden, paradojalmente, realizarse en pleno con la elección de la mejor posibilidad, sin dejar de ser categorías proyectivas, pues al consumarse en los hechos una elección, la futuridad reaparece en eso mismo en la medida en que una nueva situación nos acoge con idéntica problemática" (Cossio, L. 1845, p. 243).

Cossio establece una distinción entre valores positivos puros y valores positivos empíricos; los primeros se ubican en la infraestructura social y por eso son pre-normativos, constituyendo un canon para los valores positivos empíricos y pueden ser negados empíricamente por desvalores positivos. Los valores positivos empíricos se ubican en la superestructura social y, en cuanto se refieren a las conductas en interferencia intersubjetiva (ámbito jurídico) son el objeto ineludible de investigación y parte esencial de las diversas ciencias jurídicas (normativas, históricas y sociológicas).

\section{e) Principales propuestas ideológicas, políticas, jurídicas, actitud ante el progreso social}

La visión cossiana de la historia política y de los tipos de gobierno (con sus correspondientes notas axiológicas) se centra en su teoría de la opinión pública, tal como la desarrolla en su libro homónimo.

Hay que decir, en primer lugar, cuál es el concepto de "ideología" que asume Cossio, a fin de evitar confusiones. En el Prefacio a la $4^{\circ}$ edición de La opinión pública advierte: “...deseo aclarar que cuando en el presente libro hablo de 'ideología' lo hago en el sentido estricto y originario con que el tema entró en el dominio de la ciencia social merced a una intuición del general Bonaparte, entonces primer cónsul de Francia, esclarecida años más tarde por el análisis que sobre ella montó Carlos Marx en uno de sus momentos de mayor inspiración filosófica. Dentro de mi propia filosofía, esta noción como error axiológica se contrapone a la de verdad estimativa que la filosofía egológica justifica” (Cossio, 1973). 
Políticamente, Cossio no tuvo actuaciones partidarias, si bien tuvo ideas firmes y expresadas con decisión. En su Prefacio a la $3^{\mathrm{a}}$ edición de La opinión pública señala que fue concebido y escrito como capítulo final de su libro La política como conciencia, al buscar un instrumento que le permitiera meditar con claridad sobre la situación política y social de su país, después del derrocamiento de "un cesarismo popular despótico que lo oprimió por casi una década, precedido por una dictadura reaccionaria que duró tres años y seguido por un gobierno de liberación acentuadamente negativo, durante un tiempo similar" (Cossio, L. 1973, p. 15).

Le interesaba la política como fenómeno social. En su concepto, el curso de los sucesos históricos no es igual según que esté orientado por ideas o carezca de ellas, y las ciencias e la cultura muestran la exigencia de valoraciones objetivas. La opinión pública, decisiva en la vida política, gira en torno a la aceptación de un valor y el rechazo de un desvalor. El proceso es explicado en cuatro etapas (Cossio, L. 1974, p. 45 ss). El primer estado es el de la creación original: todo valor se origina en la creación de un individuo, porque los valores existen para un espíritu, y el espíritu existe en forma de persona individual. El segundo estrato lo constituyen grupos de personas, que se apasionan por el valor de origen y lo difunden, considerando esta tarea como una vocación. Estamos entonces aquí frente al fenómeno de la socialización del valor. Naturalmente hay creación artística, científica o deportiva en solitario, pero la ciencia, el arte, el deporte, la política, exigen la comunidad, son un fenómeno social. En este estrato, la opinión todavía no es opinión pública, sino opinión técnica, porque se trata de grupos especializados, dedicados al esclarecimiento y desarrollo del valor que los convoca. En el tercer estrato, hay ya un público que cumple esta función, con otras características. Consideremos el siguiente ejemplo (de Cossio): el hecho social de un concierto. Hay allí un valor original, el creador de la música, un segundo estrato constituido por los músicos que lo interpretan, los músicos, críticos, profesores de música y demás profesionales o entendidos en el tema, que asisten al concierto. En tercer lugar está el resto del público, convocado por su interés y gusto musical, aunque la música no séale objetivo ni la vocación de sus vidas. Entre el segundo y el tercer estrato hay una diferencia, pero no una ruptura. Los juicios de los expertos, incluyendo su base objetiva de valoración, están subjetivamente interiorizados en la experiencia musical de los oyentes, sin necesidad de una exteriorización intelectualizada.

Del mismo modo, en la vida política, la opinión pública constituye el tercer estrato, sin el cual no habría propiamente vida política. Cossio 
insiste en ese aspecto subjetivo y hasta emocional de la opinión pública, pues se niega a considerarla en forma intelectualista, como un problema de saber o no saber. Es cierto que la verdad, así como la ignorancia o el error son situaciones intelectuales, pero eso no es todo. Lo que une a la opinión pública tras un ideal político, o un valor, no es un mero "saber" acerca de ese valor, sino que es ante todo la emoción de esa verdad compartida lo que le otorga vigencia y efectividad. Finalmente, hay todavía un cuarto estrato, el de la indiferencia, la masa. Está en la base de la estratificación y también hay que contar con él.

Las expresiones de Cossio, que suenan peyorativas "hombre masa" y "hombre rebaño" (Cossio L.1974, p. 65 ss), deben ser correctamente entendidas. En primer lugar, no significan la gente pobre ni el proletariado, no es una categoría económica ni un estrato social, es una manera de instalarse en el mundo de la vida, y esto no en forma general, sino más bien parcial y circunstanciadamente. "El hombre masa es una modalidad vital que se define por la actitud que toma el individuo para con su propio mundo; por eso transparece más vale como una mentalidad o psicología [...] una misma persona contiene varias estratificaciones según el ámbito de valor en que se encuentre proyectada; puede ser masa para un determinado deporte o la pintura, opinión pública para la política o la poesía, opinión técnica para la medicina o la arquitectura y acaso creador en alguna de ellas" (Cossio, L. 1974, pp. 65.66). Por eso los nexos societarios son tan complejos y tan fluidos. Señala incluso que no existe ningún individuo que no sea masa (es decir, que no se comporte como masa) en un determinado aspecto, y esto es algo importante para la comprensión del proceso democrático.

Aplicando estas ideas a la política en concreto, señala Cossio (L. 1974, p. $74 \mathrm{ss}$ ) que todos ellos existen y no pueden faltar) en la vida democrática, y que por tanto ningún elitismo (por ejemplo el voto calificado) está justificado. Pero Cossio no fundamenta aspectos claves de la democracia como el voto universal en un igualitarismo puramente numérico; para él, a la inversa, es el igualitarismo el que se fundamenta en el hecho de una general sensibilidad de masa y en su efecto constitutivo de la mismidad del grupo social como hecho en bruto. La mismidad de un grupo social como hecho radica en lo que sus componentes tienen en común.

La democracia requiere, pues no sólo ciudadanos calificados (el segundo estrato) sino también hombres que compartan la mismidad del hecho social (tercer y cuarto estratos), cada uno con diferentes sensibilidades políticas, pero todas válidas. Incidentalmente se hace cargo de la paradoja 
de la legitimación democrática de un régimen dictatorial: la contradicción de una libertad que se anula a sí misma con su propio funcionamiento. Cossio señala lúcidamente por qué esta contradicción puede producirse y de hecho se ha producido repetidas veces en la historia: las masas (el cuarto estrato) no viven esta contradicción porque no subsumen el caso concreto en sus principios para comprenderlo. Sólo el tercer estrato puede vivir esta contradicción. Y si declarara su fe democrática pero aceptara el fraude político, dejaría de ser democrática, habría perdido su razón de ser. De ahí la "superchería" (la expresión es de Cossio) de la llamada "democracia de masas", que es en realidad un espécimen inventado por las ideologías totalitarias.

Cossio justifica la revolución y la ruptura del orden democrático cuando éste ha dejado de ser real, para transformarse en un fraude formal. El tercer estrato, en la situación de contradicción,

"para salvarse, está compelido a recomendar, con una justificación inapelable el recurso a la fuerza para dominar el conflicto. Se trata de una actitud irrenunciable para la opinión pública democrática porque va en juego el valor de la libertad política, libertad política de la que las masas hacen uso sin semejante valoración en un acto que, en tal hipótesis, da a la fuerza física el sentido de ultima ratio para aquella opinión pública" (Cossio, L. 1974, p. 83).

Un tema político-jurídico que interesó a Cossio desentrañar, es el mecanismo de la censura ${ }^{2}$. Partiendo de la observación del hecho (casi todos los Estados tienen algún mecanismo de censura) y luego de historiar brevemente las causas de la censura a la prensa en los regímenes monárquicos del s. XIX y principios del XX, concluye que los intereses autoritarios justificaron la censura con el argumento de que la intelectualidad rebelde relajaría el orden social y atraería la anarquía. Pero estos vaticinios no se cumplieron y los regímenes democráticos han probado que pueden funcionar sin censura. Este reconocimiento del carácter ordenado y legítimo de la libertad de opinión y la divergencia fue un logro de la filosofía individualista, según Cossio (aunque él no comparte todas sus asunciones). También fue positiva para la ciencia, porque en ambos casos permite que

2 Le dedica varios parágrafos de La opinión pública: "Exégesis de la censura en la trayectoria del periodismo", "Dimensión burocrática y policial de la censura política", "La censura eclesiástica como moral cristiana" y "La censura eclesiástica como ascetismo cristiano". 
el discurso se remodele de acuerdo con la verdad de la realidad (Cossio, L. 1974, p. 151).

\section{f) Ideas sobre el desarrollo de la ciencia, la técnica y la modernización}

Las ideas maduras de Cossio sobre estos aspectos están en gran parte contenidas en la cuarta edición de su libro La opinión pública. Con respecto a la tecnología y la "modernización" en el sentido de aceptación de los recursos tecnológicos, tiene una postura más bien reticente en relación a la sociedad, por su posible influencia negativa. Dice en el Prefacio a la $4^{\text {a }}$ Edición: "Finalmente deseo recordar el temor que expresa Herbert Marcuse en el sentido de que la pasmosa tecnificación alcanzada por los medios masivos de comunicación pueda ahogar a la opinión pública. Marcuse no conoce la distinción entre opinión pública y opinión popular, cosa que no cabe pasar por alto para la cuestión" (Cossio, L. 1974, p. 12). Sin embargo, no es un crítico de la ciencia ni de la tecnología en sí mismas, a las cuales considera valores de alto rango en su plexo axiológico. Le preocupa, en cambio, el modo como puedan ser usadas por los poderes de control, especialmente los políticos, según manifiesta al final del Prólogo mencionado. En este sentido, la postura de Cossio se acerca notablemente al liberalismo tradicional inglés, al estilo de Popper.

La tecnología en relación a la sociedad y la comunicación social mereció diversas consideraciones. Ya en la primera edición de La opinión pública advertía (L. 1974, p. 131) que la gente aún no había comprendido lo que puede significar la tecnología como alteración de las costumbres, por su efecto insensible y permanente en la vida de todos los días. Le preocupaban especialmente avances tecnológicos vinculados a la comunicación y la educación, como el cine, la radio y la televisión. Advertía que el mayor impacto se ejercería sobre el hombre del segundo estrato, el que comprende su importancia e incluso espera beneficiarse -sobre todo económicamentecon ellos. Teniendo una posible función social, pueden perderla fácilmente y de allí la responsabilidad que en este aspecto tiene el intelectual. Las nuevas tecnologías de comunicación, nos dice (L. 1974, p. 138), tienen mayor aptitud para expresar la verdad que el papel escrito (y la prensa), porque la imagen "miente menos". Pero además, representan "la más paradójica síntesis de masa y minoría que quepa imaginar; síntesis que también emerge de su contextura funcional y que se compagina al pelo con las condiciones de la sociedad moderna, advenida irrevocablemente como sociedad de masas por obra de la desanalfabetización y de la técnica" (L. 1974, p. 139). Porque ellos son, de nacimiento, un medio de esparcimiento, 
un "juego" para disfrutar. Y en ese sentido son consumidos de manera pasiva.

g) Concepciones sobre el papel de la educación, del arte y la literatura y sobre los métodos más adecuados para el perfeccionamiento humano

Cossio valora la educación en todos sus niveles y aspectos, como un modo de lograr una sociedad mejor. Para eso se requieren dos condiciones: 1. que el contenido educativo sea de calidad y 2. Que haya libertad en sus manifestaciones. Por eso escribió una obra especialmente dedicada las funciones educativas informales, pero decisivas, del periodismo, el cine y la televisión. Advirtió tempranamente (puesto que su preocupación se remonta a 1926) la importancia de la formación de la opinión pública y para eso propone "...poner en circulación diarios y revistas o canales de televisión destinados únicamente a la opinión pública, como ya ocurre en el cine con las películas de alta calidad. Si es cierto que la opinión pública escapa o puede escapar del engaño masivo por propia naturaleza y si sus voceros fuesen hombres e auténtica vocación decididos a no entregarse ni claudicar, la circulación de la opinión pública no podría ser impedida por la competencia ni por el soborno. Pues es difícil sobornar a un hombre que en su vocación siente a su destino; y parece imposible restar lectores a nivel de opinión pública con los medios que traen los periódicos y canales de nivel popular" (Cossio, L. 1974, p. 13).

\section{h) Opiniones sobre la cultura latinoamericana e iberoamericana en general, sus nexos con la cultura universal y en especial el lugar que ocupa dentro de ellas la filosofía.}

Aunque no fue un tema central en su trabajo, es indudable que Cossio valoró positivamente las capacidades reflexivas y filosóficas de los latinoamericanos, incluso tomando por ejemplo su propio caso y el de sus discípulos e interlocutores. No parece haber experimentado ningún tipo de "complejo de inferioridad" frente al pensamiento europeo, al que trataba de igual a igual, con reconocimiento de la otra parte. En su artículo sobre la visita de Kelsen a la Argentina se reproducen las discusiones tenidas entre ambos y con intervenciones de otros pensadores argentinos. Afirma que la escuela egológica, al tomar como punto de partida (y también luego, de crítica y distanciamiento) la teoría kelseniana, dio a su autor un lugar importante entre los argentinos. Kelsen quería dialogar con los pensadores egológicos, pero -continúa Cossio- sólo tenía un conocimiento fragmentario de la teoría debido a su desconocimiento del castellano: 
"Kelsen apenas conocía la traducción alemana de 'Norma, Derecho y Filosofía', la traducción inglesa de la "Fenomenología de la Sentencia" (que corresponden a las 65 páginas iniciales de las 450 que hacen "La Teoría Egológica del Derecho" y una traducción alemana del artículo "¿Cómo ve Kelsen a la Teoría Egológica del Derecho?", que publiqué en Revista La Ley, t. 52, p. 1075. Para aclarar su propia cuestión, aquel porqué para él clave e ineludible, no tenía más recurso que el contacto personal y la vía oral"3. En este párrafo no hay ninguna exageración, porque es cierto que Kelsen, al visitar Argentina, se interesó muy especialmente por dialogar con Cossio y su grupo; por otra parte, muestra también que su obra tenía repercusión en ámbitos sajones ya en 1949 y que en esos ambientes se consideraba de interés una contrastación disputativa entre la Teoría Pura y la Teoría Egológica. El diálogo entre ambos, que se reproduce en este artículo, muestra a dos pensadores discutiendo en pie de igualdad y con el trasfondo de la filosofía universal. Kelsen no habla de la Teoría Egológica como "filosofía latinoamericana" y Cossio tampoco: ambos tratan, con los recursos teóricos de su propia elucubración, diversos problemas. Es interesante dar un ejemplo de este diálogo (2003, n. 10, p. 43).

Kelsen objeta que la Teoría Egológica tiene un punto de partida metafísico y él rechaza toda metafísica. Este punto es considerar la libertad como algo real existente, un ente no reconocido por la ciencia. Cossio contesta que sólo la ciencia natural no conoce a la libertad porque no está en su ámbito, sino en el ámbito de la cultura y de la historia, que se ocupan del tiempo espiritual. Kelsen objeta que no ve con claridad este concepto de filosofía de la cultura y que hacía 20 años había escrito un trabajo criticando a Rickert. Cossio argumenta que la filosofía de la cultura no se agota en Rickert, sino que incluye a Dilthey, Bergson, Husserl, Scheler, Heidegger y Ortega y Gasset. Kelsen insiste en que todos los nombrados son metafísicos y que él ya ha tomado posición contra la metafísica, a lo que Cossio responde que en realidad Kelsen no prescinde de la metafísica sino que reemplaza una metafísica de la libertad por otra del determinismo. El diálogo opositivo continúa con diversas consideraciones de tenor similar. Lo que interesa es mostrar que para Cossio la filosofía (y la iusfilosofía) es universal, que los autores y las teorías son patrimonio de todos y que lo importante es el planteamiento y resolución de los problemas.

Cossio se sentía orgulloso del éxito de la Teoría Egológica (es decir, de una teoría filosófica, que implica un pensamiento objetivado asumido

3 "Teoría egológica y teoría pura", cito por Páginas de Ayer, 2003, n. 10, p. 35. 
por muchos otros además de él mismo, y completado y desarrollado a través de la crítica). Y la defiende de las malas interpretaciones. Bastará un solo ejemplo ${ }^{4}$ : Luis Jiménez de Asúa, célebre penalista español que fue varios años profesor en la Universidad de La Plata luego de la caída de la república española, formuló una crítica indirecta a la teoría egológica en la cual, veladamente (o no tanto) se la tachaba "de germinadora de espíritu nazificante", al cuestionar tanto la noción estructural del delito como la aceptación de la función creadora del juez penal. Ésta y similares críticas le parecen inspiradas en falacias ideológicas. Y como respuesta, en el parágrafo 5 de ese artículo generaliza la defensa, y retóricamente se pregunta (aceptando aquí explícitamente su origen latinoamericano) (2003, n. 4, p. 54): "En este sentido cabe preguntar qué es la teoría egológica para tener esa diabólica virtud que la hace propagarse en una forma sin precedentes en la historia de las ideas jurídicas latinoamericanas; y que a unos arrebata y a otros irrita, pero que a todos conmociona, hasta el punto que hoy, en la Argentina, existen sólo los egológicos y los anti-egológicos, sin un territorio intermedio para un campo neutral, por su indiferencia". Parece molestarle particularmente que se desconozca la originalidad de su teoría y en consecuencia que sus adherentes sean llamados (por Jiménez de Asúa por ejemplo) "afiliados al kelsenismo argentino" o "neokelsenianos platenses"; pero no por la afirmación "colonialista" o la dependencia teórica que estos epítetos pudieran implicar, sino porque no ven o no quieren ver la diferencia entre ambos pensadores. Cita en apoyo de su punto de vista a Joseph Kunz, radicado en Estados Unidos y amigo de Kelsen, para quien nadie en Latinoamérica ha entendido a Kelsen mejor que Cossio, porque ha advertido que debía confrontar la filosofía del derecho con la ciencia del derecho, mientras que otros latinoamericanos, para ir más allá de Kelsen, han confrontado la teoría pura del derecho con la filosofía metafísica del derecho (2003, n. 4, p. 56). En todo este desarrollo, Cossio se posiciona como un filósofo con ideas propias y con la convicción de que su teoría pertenece al ámbito universal y en él y desde ese universalismo filosófico debe ser discutida y evaluada.

4 “El principio 'nulla poena sine lege' en la axiología egológica", cito por Páginas de Ayer, 2003, n. 4, p. 50. 


\section{BIBLIOGRAFÍA DE Y SOBRE EL AUTOR}

\section{A) Bibliografía del autor}

Es muy extensa, sólo se ha tomado una parte, que responde a los temas del trabajo y como muestreo de su producción. Se expone en orden cronológico.

\section{Libros}

- (1927) La reforma universitaria o el problema de la nueva generación, Bs. As. Espasa Calpe.

- (1936) El concepto puro de revolución, Barcelona, Bosch.

- (1936) La valoración jurídica y la ciencia del derecho, Santa Fe, Univ. Nac. del Litoral.

- (1944) La teoría egológica del derecho y el concepto jurídico de linertad, Bs.As. Losada, 1944, $2^{\mathrm{a}}$ ed. Bs.As. Abeledo Perrot.

- (1946) El derecho en el derecho judicial, Bs.As. Kraft, 1945; $3^{\text {a }}$ ed. Bs. As.

- (1947) La función social de las escuelas de abogacía, Bs.As. Fac. de Derecho y Ciencias Sociales.

- (1948) La coordinación de las normas jurídicas y el problema de la causa en el derecho, Bs. s. Alea..

- (1949) Panorama de la teoría egológica del derecho, Bs. As., Instituto de Filosofía del Derecho y Sociología.

- (1954) Teoría de la verdad jurídica, Bs. As. Losada.

- (1957) La política como conciencia, Bs. As. Abeledo-Perro.

- (1958) La opinión pública. I. Esencia. II. El periodismo. III El cine, la radio y la televisión; $3^{\text {a }}$ ed. Buenos Aires, Losada, 1958, $4^{\text {a }}$ ed. Buenos Aires, Paidos.

- (1963) La teoría egológica del derecho: su problema y sus problemas, Bs. As. Abeledo Perrot.

- (1964) La teoría egológica del derecho y el concepto jurídico de libertad, $2^{\mathrm{a}}$ ed. Bs. As. Abeledo Perrot. 
- (1969) La causa y la comprensión en el derecho, Buenos Aires, Juárez Editor.

\section{Artículos}

- (1923) "Representación gráfica del universo", Revista de Filosofía (Buenos Aires) 9, 1923, n. 5: 189-196.

- (1926) “Análisis de la no-Vulgaridad.. Contribución al concepto de 'generación' y de una determinación de las categorías de la personalidad", Nosotros (Buenos Aires) 20, 1926, n. 204: 54-72.

- (1927) “La religiosidad (fundamentación crítica de la religión)", Nosotros 21, 1927, n. 212: 21-41.

- (1940) "El sustrato filosófico de los métodos interpretativos", Jurisprudencia Argentina 71, 1940, sec. doct.,: 25-42. y en Universidad (Santa Fe) 1940, n. 6: 47-110.

- (1947) "La valoración jurídica y la Ciencia del Derecho", Universidad (Santa Fe), 1941, n. 8, 7-127. En volumen, Bs. As. Ed. Arayú, 1954.

- (1947) "El principio 'Nulla poena sine lege' en la axiología egológica", La Ley, 1947, t. 48: 1135-1152, y en Páginas de ayer 4, n. 4, 2003: 39-56.

- (1949) “Teoría egológica y teoría pura. Balance provisional de la visita de Kelsen a la Argentina", La Ley, 1949, t. 56: 835-861 y en "Páginas de ayer", 4, n. 10, 2003: 30-35.

- (1949) "Panorama de la teoría egológica del derecho", Revista de la Facultad de Derecho y Ciencias Sociales, 3 época, 4, 1949, n. 13: 57-100.

- (1950) "La filosofía y la ciudad humana", Actas del Primer Congreso Nacional de Filosofia (1949), 1950, t. 1: 547-550.

- (1952) "Circunstancia de la aparición egológica", La Ley, 1952, t. 67: 752-767.

- (1952) “El ser del Derecho”, La Ley, 1952, t. 68: 741-753.

- (1952) “El ser de la norma”, La Ley, 1952, t. 68: 759-771 y en "Páginas de ayer" 4, n. 3, 2003: 8-22. 
- (1852) "Constitución de la experiencia jurídica", La Ley, 1952, t. 68: 915-934.

- (1953) "Las posibilidades de la lógica jurídica según la lógica de Husserl", Revista de la Facultad de Derecho y Ciencias Sociales (Buenos Aires), 1953, n. 23: 201-241.

- (1954) "La polémica anti-egológica (respuesta al profesor Hans Kelsen)", La Ley, 1954, t. 76: 740-760.

- (1956) "Las actitudes filosóficas de la ciencia jurídica”, La Ley, 1956, t. 82: 753-762.

- (1956) "Los valores jurídicos. Meditación sobre el orden y la seguridad", La Ley, 1956, t. 83: 1015-1025.

- (1959) "La lógica jurídica formal en la concepción egológica", La Ley, 1959, t. 93: 917-931.

- (1961) “La gnoseología del error”, La Ley, 1961, t. 101: 1079-1102.

- (1962) "La crítica de la jurisprudencia dogmática como crítica de nuestra época”, La Ley, 1962, t. 108: 1088-1092

- (1965) "Las ideologías", Actas de las Segundas Jornadas Universitarias de Humanidades (1964) Mendoza, 1965: 417-420; reproducido en Aislamiento y Comunicación, 1966: 74-81.

- (1967) "El derecho y sus valores parcelarios", La Ley, 1967, t. 126: 934938.

- (1967) “La justicia”, La Ley, 1967, t. 126: 1037-1049.

- (1967) "La filosofía de la filosofía en el derecho natural”, La Ley, 1967, t. $127: 1310-1323$.

- (1867) "El derecho natural y la norma fundamental”, La Ley, 1967, t. 128: $1067-1083$.

- (1967) “La egología y el derecho natural”, La Ley, 1967, t. 127: 14131422.

- (1972) “Crítica egológica del tridimensionalismo jurídico”, La Ley, 1972, 1972, t. 147: 1360-1381. 


\section{B) Bibliografía sobre el autor}

Como se ha señalado, las teorías de Cossio suscitaron muchas discusiones filosóficas más que trabajos de exposición histórica de su pensamiento. Se ocuparon de él los juristas y iusfilósofos más que los historiadores de la filosofía. A continuación se elencan algunos trabajos que discuten las teorías de Cossio y que fueron publicados mientras él vivía, varios de los cuales son mencionados por él mismo, para manifestar su acuerdo o su disenso.

- (1956) Aftalión, Enrique - Fernando García Olano - José Vilanova, Introducción al derecho, Bs. As. $5^{\text {a }}$ edición, (aumentada y sucesivas) 1956 (las anteriores eran firmadas sólo por Aftalión y García Olano; los autores, discípulos de Cossio, le dedican numerosos parágrafos a su teoría).

- (1947) Brandao, Antonio José, "Fenomenologia da sentença", Boletim do Ministero de Justiçia (Lisboa), n. 2, 1947 (en p. 307 ss la considera la más notable superación de la teoría pura del derecho).

- (1947) Castán Tobeñas, José, Las diversas escuelas jurídicas y el concepto del Derecho, Madrid, Reus, 1947 (se refiere a Cossio en pp. 40 a $53)$.

- (1945) Frías Caballero, Jorge, "El concepto jurídico del delito y otras cuestiones", La Ley, t. 38, 1945, p. 1073 ss. (no comparte las críticas a la teoría estructural del delito).

- (1946) Goldschmidt, Werner, "En torno a la Escuela Egológica del derecho", Revista Crítica de Derecho Inmobiliario, 22, 1946, n. 221 (reconoce a la teoría egológica como un significativo esfuerzo por crear una teoría iusfilosófica moderna).

-1947) Ibáñez de Aldecoa, Alfonso, "Revelación, Filosofía y Derecho", Revista de Información Jurídica (Madrid) n. 50-51, 1947 (p. 95 ss. desde la escolástica considera que el egologismo es una verdadera innovación en la investigación iusfilosófica).

- (1945) Jiménez de Asúa, Luis, "La ley penal y su interpretación”, El Criminalista 5, 1945, pp. 216-217 (cercanía a la posición egológica aunque en otros escritos la critica). 
- (1947) Legaz y Lacambra, Luis, "La concepción egológica del Derecho", Revista de Información Jurídica (Madrid), n. 53, 1947 (en p. 23 ss. la considera la aplicación más lograda del existencialismo al pensamiento jurídico).

- (1947) Naranjo Villegas, Abel, Filosofía del Derecho, Bogotá, 1947 (en p. 24 ss la considera la aplicación más notable de la fenomenología a la iusfilosofía).

- 1947. Núñez, Ricardo C. “¿Debemos abandonar la manera tradicional de aplicar la ley penal?", Revista Jurídica de Córdoba, 1, 1947, n. 1 (análisis fundamentado de la teoría egológica en su aplicación al ámbito penal).

- (1947) Reale, Miguel, "La teoría estimativa del derecho", Revista da Faculdade de Direito de São Paulo, v. 34, 1947 (p. 136 ss considera que la originalidad de Cossio es conciliar, en la esfera del Derecho, la fenomenología con el formalismo kelseniano).

- (1977) Vilanova, José, Elementos de Filosofía del derecho, Bs. As. 1977, $1^{\text {a }}$ ed. 1984 (el autor fue discípulo de Cossio "de quien tomé casi todo lo que no me exigió fundada disidencia"). 